\title{
Relato de quem ousa ensinar com amor
}

Charles Amorim Mendonça ${ }^{1}$

\section{Resumo}

Neste relato desejo partilhar a experiência pedagógica freireana que vivenciei na Educação de Jovens e Adultos (EJA) da Escola Estadual Catarina Jorge no ano de 2017, no município de Contagem, Minas Gerais. Foram duas turmas que naquele ano cursaram o primeiro e o segundo ano do Ensino Médio, tendo 59 alunos. Utilizei a metodologia dos Círculos de Cultura e debate, acompanhando o processo de maturação e leitura do mundo por meio de sua realidade social a fim de promover o ser mais no educando.

\section{Palavras-chave}

Ensino. Aprendizagem. Temas Geradores.

\footnotetext{
${ }^{1}$ Especialista em Docência do Ensino Religioso pelo Instituto Pedagógico de Minas Gerais, Brasil; professor da rede municipal de ensino de Betim, Minas Gerais, Brasil. E-mail: charlesamorim@ hotmail.com.
} 


\title{
A report by someone who dares to teach with love
}

Charles Amorim Mendonça²

\begin{abstract}
In this report I want to share the Freirean pedagogical experience that I experienced in Youth and Adult Education (YAE) at Catarina Jorge State School in 2017, in the city of Contagem, State of Minas Gerais, Brazil. There were two classes that year, in the first and second year of high school, with 59 students. I used the methodology of Culture Circles and debate, following the process of maturation and reading of the world through its social reality in order to promote being more on the student.
\end{abstract}

\section{Keywords}

Teaching. Learning. Generating Themes.

2 Specialist in Teaching of Religious Education, Pedagogical Institute of Minas Gerais, Brazil; teacher at the municipal school system in Betim, Minas Gerais, Brazil. E-mail: charlesamorim@ hotmail.com. 


\section{Introdução}

Este é um breve relato das experiências de um professor que teve o prazer de lecionar temporariamente sociologia por meio de contrato com o Estado. Apaixonado por uma educação humanizante e humanizadora. Essa experiência se deu no ano de 2016, na Escola Estadual Catarina Jorge, no bairro Água Branca, no Município de Contagem, Minas Gerais, onde lecionei Sociologia para os alunos e alunas da Educação de Jovens e Adultos (EJA).

Tínhamos em torno de 59 pessoas matriculadas entre 17 e 75 anos, desde amantes da leitura a pessoas avessas ao gosto pelos estudos. Os mais interessados em estudar eram os mais velhos, pois mantinham maior interesse e participavam de forma ativa das aulas (que preferimos chamar de encontros) e os mais relapsos eram os jovens. Muitos estavam ali com o objetivo de concluir o ensino médio para ingressarem no mercado de trabalho, sem muita perspectiva e interesse na vida acadêmica. Utilizamos os Círculos de Cultura e os Temas Geradores como uma prática freireana para proporcionar aos educandos um processo de amadurecimento e reflexão do seu contexto social e sua participação na política em busca da construção de uma sociedade melhor.

Dessa forma, este texto está estruturado em três partes: na primeira, busco mostrar como se deu minha proximidade com a pedagogia de Paulo Freire, o que transformou minha forma de ensinar, colocando sempre o diálogo como principal método de ensino em busca de um espaço de educação mais democrático. Já, na segunda parte, trouxe a metodologia freireana, tratando sobre o Círculo de Cultura e os Temas Geradores. E, na terceira parte, intitulada Como tudo aconteceu, mostro como se deu minha prática em aula, relacionando isso à alfabetização dos candangos na construção de Brasília.

\section{Como se deu a proximidade com Paulo Freire}

Meu primeiro contato com Paulo Freire se deu ao ler Pedagogia da Autonomia (2002), mais ou menos em 2008, quando eu era aspirante à vida religiosa consagrada Marista. Já tinha ouvido falar dele e da forma como revolucionou a educação com seu jeito de pensar e agir, mas ainda não tinha lido nenhuma de suas obras. Até que, na biblioteca da comunidade religiosa, encontrei aquele pequeno livro, rico de conteúdo. Devido às rotinas da comunidade e à escassez de tempo, deixei para lê-lo como uma leitura de férias; aquela leitura me instigou e me inquietou muito. O que mais me seduziu nessa leitura era como Paulo Freire ensina a nós, professores e professoras, que devemos instigar os educandos a serem pessoas que 
busquem o ser mais como uma ação transformadora da vida e da realidade do indivíduo. E essa transformação acontece por meio da educação. Para realizar esse caminho, nos diz sobre ética crítica, competência científica e sobre o amor e o engajamento político, iluminando nossa ação de educadores no relacionamento com nossos educandos.

Muito me chamou a atenção entre a leitura de Freire e o que São Marcelino Champagnat desejou aos irmãos maristas quando fundou o instituto em 1817 para a educação das crianças e jovens pobres, pois ele queria educação de qualidade para as crianças e jovens. Por isso, desejava ter irmãos colaboradores nessa missão. O padre Champagnat era filho de camponeses pobres da França. Dizia Champagnat (2011, p. 35), "para bem educar as crianças é preciso, antes de tudo, amá-las, e amá-las todas igualmente”. O barulho das crianças nas escolas Maristas deveria “ser canções para os irmãos” (CHAMPAGNAT, 2011, p. 105). Tudo muito relacionado com o jeito de ser de Paulo Freire. Assim, nesse útero eu fui gerado como educador, saciando uma sede pedagógica totalmente humanizante e humanizadora.

O diálogo sempre reinou em nossos encontros, nunca foram aulas, mas momentos que promoviam descobertas e o ser mais. Assim, as turmas desejavam sempre mais que nos encontrássemos para aprimorarmos nosso saber e construirmos mais redes de conhecimento. Era um espaço pedagógico democrático, sem monopólio do saber e nem monólogo do mediador.

\section{Apropriando-se da metodologia freireana}

Ao propor os Temas Geradores como uma parte do processo de ensino-aprendizagem, Paulo Freire nos convida a um caminho novo, para tratar questões do conhecimento epistemológico. A novidade da pedagogia freireana se encontra na elaboração de uma metodologia coerente para o processo de preparação do conhecimento. Para esse fim, são propostos os Temas Geradores como um caminho de superação, tanto do dualismo objeto e sujeito quanto o da separação do saber, decorrente do paradigma científico moderno por causa da verticalização do saber, que conduz a uma ciência sem vida e desumana. Por meio da metodologia de Temas Geradores, que mexem com o cotidiano das pessoas e as provoquem para entrar em uma discussão dialógica da construção e da desconstrução de conceitos próprios do cotidiano. Utilizando-se deles para elaboração de novos conhecimentos, me dispus a trabalhar com essas duas turmas com círculos de debates, em que, através de uma palavra geradora retirada do contexto social ou político vigente, discutíamos temas conceitos 
que tocavam as nossas realidades. Lembro-me do debate acirrado em torno do processo de impeachment de Dilma Rousseff. Os prós e os contras de cada um e de cada uma.

Para ser coerente com o pensamento freireano, os Temas Geradores se transformam em uma forma de conceber o conhecimento e a formação do ser humano. Por isso, exige troca de saberes, o que ocorre nos Círculos de Cultura. Para Paulo Freire não existe uma separação entre seres humanos sábios e ignorantes, ele acaba com a ideia de "tábula rasa" na qual os educandos e educandas não têm nada a contribuir com a construção do conhecimento e os "detentores do saber", o educador ou educadora, possui conhecimento para transmitir, com esse pedantismo de uma cultura das elites com o formalismo científico.

Nessa perspectiva, percebe-se que os temas direcionam para a troca de saberes por intermédio do diálogo, que respeita as diferenças de cada um com sua própria visão de mundo. Essa proposta é uma superação de uma visão de mundo inocente, muitas vezes ingênua, para uma visão crítica, que leve o homem a assumir-se como sujeito responsável, como autor de sua trajetória sócio-histórica num todo, que seria o diferencial nos fundamentos de pedagogia bancária (FREIRE, 1993) para a problematizadora; do saber alienante e autoritário para o saber libertador/conscientizador; de uma ciência necrófila (que atrofia todo o potencial do ser humano de ser mais) para uma ciência biófila (que potencializa a criatividade, que impulsiona o ser humano na busca do seu ser mais). Enquanto na concepção "bancária"

o educador vai "enchendo" os educandos de falso saber, que são os conteúdos impostos na prática problematizadora, vão os educandos desenvolvendo o seu poder de captação e de compreensão do mundo que lhes aparece, em suas relações com eles não mais como uma realidade estática, mas como uma realidade em transformação, em processo. (FREIRE, 1993, p. 71).

A ideia inovadora da pedagogia de Paulo Freire tem um viés epistemológico, isto é, a visão dialética no processo de construção do conhecimento. Ela se inicia com a concepção de que todo ser humano é detentor de conhecimentos, não importando sua idade, nem o meio onde está inserido, como também a sua escolarização. O conhecimento está na reunião de saberes que estabelecem sua visão de mundo, com todas as suas contradições e coesões. Isso se dá não em uma forma isolada e estanque, mas a partir das trocas de conhecimento que ocorrem nas nossas relações sociais ou em processos formais ou informais que produzem uma criação e uma recriação de forma contínua do conhecimento. Por isso, o ser humano está em constante construção e reconstrução. É sempre uma obra inconclusa, um ser que busca 
continuamente se aprimorar. Pois é errando que se aprende e se aprende errando; um processo cíclico.

Concluo que a intenção dos Temas Geradores foi provocar uma tensão entre o saber já edificado e o saber em construção, a partir do diálogo em grupo e das leituras indicadas, além da compreensão de mundo que cada um e cada uma trazia para sala de aula. Nosso conhecimento passou a ter bases sólidas na ânsia do ser mais, na busca de sonhos possíveis no processo de libertação da educação e no rompimento do senso comum. A partir da realidade da pessoa e do seu nível de compreensão de mundo, possibilitando desencadear a discussão problematizadora, que é explicitar as ideias diferentes de cada um e cada uma, trazendo para o círculo de debates aquilo que são temas geradores, para provocar novos níveis de consciência e conhecimento da realidade, ressignificando sua visão de mundo.

Para Freire (1993), o conhecimento se dá por meio do diálogo e da permuta de conhecimentos, em que professor e estudante são igualmente dependentes do aprendizado. Entre educador e educando é necessário cumplicidade no processo de ensino-aprendizagem, pois, por meio dele, o docente tem condições de identificar as dificuldades do discente e oferecer auxílio no esclarecimento de dúvidas sobre o que está aprendendo e sendo ensinado. O professor se torna um pontífice, um construtor de ponte e um mediador do conhecimento. Conforme Freire (1987, p. 39), o educador “já não é o que pensa educar, mas o que, enquanto educa, é educado, em diálogo com o educando que, ao ser educado, também educa. Ambos, assim, se tornam sujeitos do processo em que crescem juntos e em que os 'argumentos de autoridade' já não valem".

O conceito de Dialogicidade de Freire (1993) em Pedagogia do Oprimido nos aponta uma ação coletiva e libertadora, em que a problematização embora sistematizada num senso crítico e coletivo, o que permite uma interação e conflitos na busca da prática educativa humana com empatia e, ao mesmo tempo, uma análise crítica. Esse movimento por meio do diálogo possibilita entendermos, no âmbito geral, o processo da construção humana, bem como para o educador e para o educando. Segundo Freire (1980, p. 9), “A educação é comunicação, é diálogo, na medida em que não é a transferência de saber, mas um encontro de sujeitos interlocutores que buscam a significação dos significados". Entendemos, assim, que a dialogicidade é uma contribuição na construção e na reconstrução do sujeito, a partir de um diálogo latente, permitindo uma relação dialógica com respeito e responsabilidade. 


\section{Como tudo aconteceu}

Pela segunda vez na minha vida eu iria trabalhar com a EJA, mas era a primeira como professor. Havia sido contratado pelo Estado naquele ano para assumir aquelas poucas aulas que estavam à disposição. Porém, as assumi com muito ímpeto e coragem. Tive a graça de ter um coordenador pedagógico que sempre me apoiou nos meus projetos e na minha dinâmica diferente de lecionar. O primeiro dia de nossos encontros, de fato foi um encontro, como descreve Antoine de Saint-Exupéry, em o Pequeno Príncipe, na passagem do Príncipe em seu diálogo com a raposa:

Se tu vens, por exemplo, às quatro da tarde, desde às três eu começarei a ser feliz! Quanto mais a hora for chegando, mais eu me sentirei feliz. Às quatro horas, então, estarei inquieta e agitada: descobrirei o preço da felicidade! Mas se tu vens a qualquer momento, nunca saberei a hora de preparar meu coração... É preciso que haja um ritual (SAINT-EXUPÉRY, 1987, p. 50).

Em nossas vidas temos que ter o ritual de nos prepararmos, é preciso aquecer e preparar o coração para cada encontro, a fim de que ele se torne significativo. Por isso, o medo abriu espaço para a coragem e a ousadia de estar diante da turma em apresentar-me e deixar com que eles se apresentassem a mim. Ao chegar ao local de nossos encontros, propus que abrissem um círculo e combinamos que o espaço seria organizado assim para os nossos momentos às quartas-feiras. Dessa forma, levaram um enorme susto, pois o quadro e o professor não seriam mais o centro, mas sim um espaço vazio a ser preenchido com diálogo, com círculos de cultura e de debate à luz dos temas geradores.

Foi muito rico perceber que as senhoras e os senhores, formados e formadas na educação bancária, questionaram como se daria o processo de transmissão do conhecimento. E o que vamos aprender? O que vamos anotar? Como vamos adquirir conhecimento com essa prática? Sempre com muita lucidez de um processo pedagógico que eu gostaria de propor. Assim, os apresentei como seria e expus que juntos construiríamos e conduziríamos as discussões a cada momento em que estivéssemos juntos.

Lembrei-me do processo de alfabetização dos candangos na construção de Brasília e partilhei com eles um trecho dessa história, em que as palavras geradoras deveriam jorrar do tijolo, da mão dos pedreiros das forças humanas, como a água do São Francisco jorra, de mansinho, quase invisível, da serra da Canastra aqui nas Minas Gerais, texto que foi publicado no jornal Brasil Urgente em 1963. O tijolo, essa primeira palavra geradora e libertadora, fora escolhida por eles, assim como as outras que proclamam temas de libertação. 
O saber ler brota do saber viver e do saber trabalhar. Estava lá escondida, esperando o seu toque para brotar e inundar Brasília e o Brasil. A palavra e a imagem do tijolo se decompõem e se recompõem como em uma dança circular e tomam forma de sílabas, em consoantes e vogais e, assim, formam outras palavras, viram frases, tocam vidas e começam a ser mexidas e remexidas, tornando-se fecundas em novas palavras e novas imagens, sempre dão vida ao analfabeto que brinca com as letras e vira escritor autobiográfico, como semear em terra fértil.

A mágica deu-se a partir da descoberta e da curiosidade, resultando, em um primeiro contato, em que todos se divertem com a palavra ti-jo-lo, que os educadores ajudam a fragmentar a palavra em sílabas ta, te, ti, to, tu, acompanhando ja, je, ji, jo, ju, chegando ao la, le, li, lo, lu. Após a discussão para a formação da palavra geradora tijolo, os participantes foram estimulados no jogo de combinações das famílias silábicas do ti, do jô e do lo. Imediatamente, um dos participantes demonstrando já ter compreendido o mecanismo da leitura juntou as sílabas e formou, numa linguagem bem popular, a frase: "Tu já lê" ("Tu já lês!"). Imagino compartilhar dessa alegria contigo, caro leitor amigo, você não sabe como esse método tem feito bem na vida de muitas pessoas e como nós educadores e educadoras temos tido alegrias ao ver mais e mais pessoas alfabetizadas. Como foi bonito ouvir em uma entrevista que o fenômeno do tijolo "mágico" dos candangos, quando eles saíram escrevendo pelas ruas de Brasília a palavra TIJOLO. E como foi a alegria de ver o processo de amadurecimento dos meus educandos, em nossos encontros, quando refletíamos temas como distribuição de renda, o lugar da mulher na sociedade, entre outros.

Como os candangos, seremos nós, mas não na alfabetização e sim na discussão e na mediação do nosso conhecimento à luz da sociologia, levando em conta o contexto social em que estamos inseridos aqui. O nosso ponto de partida sempre será cada um e cada uma de nós, partiremos do nosso conhecimento prévio, como baliza para a edificação de novos conhecimentos e de revisão e desconstrução de conhecimentos já adquiridos. Dessa forma, a grande preocupação era como seria avaliado o processo, pois infelizmente para o Estado o importante são as notas dadas ao aluno. Avaliamos a partir de trabalhos, de debates e de avaliações discursivas sobre os assuntos tratados naquele período em nossos encontros. E, de forma democrática, como se deu o amadurecimento de cada um nesse processo. Assim, como mediador me deixei ser avaliado. 


\section{Considerações finais}

Concluo que esse processo de ensino-aprendizagem foi desafiador, mas, ao mesmo tempo, gratificante, pois a magia pedagógica é salvadora, está na dupla leitura conexa: o sentido das palavras aprendidas é associado à realidade sofrida da vida do educando trabalhador e essas palavras se tornam vivas e provocam vida na vida das pessoas. A consciência do inacabado permite ao professor reconhecer-se como sujeito que pode ir além de inserir-se no mundo como sujeito da história e não como objeto. É preciso ser curioso, pois a curiosidade leva à busca do conhecimento, propondo e não castrando em nome da memorização mecânica do ensino de conteúdos que "não forma, domestica" (FREIRE, 1976, p. 63).

É na inconclusão do ser que se funda a educação como processo permanente. Deve-se possibilitar ser crítico, um aventureiro, porém, ético. Compreender a educação como processo perene e não estático monolítico. E como processo, não é individual, mas coletivo. $\mathrm{O}$ conhecimento é uma apropriação do indivíduo, mas seu processo de construção deve ser coletivo. É vivência, é social, não individual. É diálogo, e não monólogo.

A partir dos círculos culturais, as aprendizagens acontecem com as vivências e com os compartilhamentos dos saberes, saberes diferentes que são e que irão promover novos saberes. Nesses Círculos de Cultura é possível estabelecer a igualdade, a liberdade de expressão, a democracia e a interatividade, percebendo e respeitando modos de vida diferentes, pois cada um traz consigo sua identidade, seus pensamentos e seus valores próprios, que, ao serem compartilhados, torna-se evidente uma profunda transformação social.

Dessa maneira, visa-se formar pessoas com valores humanos e fraternos que se veem comprometidas em construir uma sociedade mais igualitária e mais justa, uma sociedade incansável na busca por direitos para todos, em que ninguém larga a mão de ninguém, em que mulheres, que eram oprimidas pelos seus maridos, sejam capazes de sair de sua situação de opressão. Hoje como é gratificante ver muitos trilhando com muita dificuldade, mas fazendo o seu caminho na vida acadêmica. Ousando sonhar sonhos possíveis. Em que o conhecimento é fonte de libertação. Como sou grato pelo bem que esses alunos fizeram e até hoje fazem na minha vida.

Com base no caminho percorrido em nossos encontros através dos círculos de debate, refletimos a nossa situação social, econômica e política e destacou-se o amadurecimento da reflexão de cada um e de cada uma na busca constante do ser mais. Tivemos estudantes que, ao concluírem a EJA, buscaram continuar sua vida acadêmica. Alguns hoje ou têm um 
diploma universitário ou estão concluindo sua primeira graduação, outros abriram seu próprio negócio como uma forma de renda. Mas vivem em busca do ser mais a cada dia.

\section{Referências}

BAPTISTE, J. P. Vida de São Marcelino José Bento Champagnat. São Paulo: Loyola, 1999.

FREIRE, P. Ação cultural para a liberdade e outros escritos. Rio de Janeiro: Paz e Terra, 1976.

FREIRE, P. Educação como prática de liberdade. Rio de Janeiro: Paz e Terra, 1967.

FREIRE, P. Os cristãos e a libertação dos oprimidos. Rio de Janeiro: Base, 1978.

FREIRE, P. Pedagogia da autonomia. Rio de Janeiro: Paz e Terra, 2002.

FREIRE, P. Pedagogia da esperança. 15. ed. Rio de Janeiro: Paz e Terra, 2008.

FREIRE, P. Pedagogia do oprimido. Rio de Janeiro: Paz e Terra, 1993.

SAINT-EXUPÉRY, A. de. O pequeno príncipe. 31. ed. Rio de Janeiro: Agir, 1987.

Submetido em 15 de julho de 2021.

Aprovado em 15 de agosto de 2021. 